\title{
A Study of Brand Communication Strategies of Xiaomi
}

\author{
Shengpeng $\mathrm{He}^{1, *, a, \uparrow}$ Shaoheng Sun ${ }^{2, *, b, \dagger}$ \\ ${ }^{1}$ School of Business, Staffordshire University at Staffordshire, Shropshire, ST4 2DF, United Kingdom \\ ${ }^{2}$ School of Business, University of North Carolina at Pembroke, Pembroke, 28372, United States \\ *Corresponding Email: ${ }^{a}$ he.shengpeng@student.zy.cdut.edu.cn, ${ }^{b}$ ss0079@bravemail.uncp.edu \\ ${ }^{t}$ These authors contributed equally.
}

\begin{abstract}
The study applied both quantitative and qualitative method, which is a questionnaire and focus group, in this study as they have advantages over panel data or time-series data. The questionnaires were collected from eight major provinces of China with 1038 participants. The research focused on the company Xiaomi, a global joint technology company whose sales volumes ranked third in the smartphone market in 2020. The first questionnaire focuses on consumers' perception of five major Chinese smartphone brands' different communication strategies and compares Xiaomi's five aspects of its brand communication strategies horizontally to determine the weak aspect of Xiaomi's brand communication strategy and then compares it with other four brands to further complete the comparison. After obtaining the result from questionnaire, a focus group was formed to investigate the possible reasons behind the result, which is the public communication strategy of Xiaomi's. Moreover, the discussion result of focus group indicated that customer insulting and exaggerated statements are two main reasons behind the failure of Xiaomi's communications strategy in terms of public communication. The finding may be able to point out the direction of correction for Xiaomi and can benefit other smartphone companies as a warning sign.
\end{abstract}

\section{Keywords: Xiaomi, Brand communication, Public communication}

\section{INTRODUCTION}

Brand communication is a powerful tool for any brand to build up the desired brand image. As Zehir stated that Brand communication aims to improve brand awareness and brand image by increasing brand exposure to consumers in a variety of ways. Brand communication enables consumers to become loyal customers of a brand in the process of repeated contact with the brand [1].

With the advent of smartphones, the cell phone market, dominated by Apple, Samsung, Nokia, etc., has undergone a structural change [2]. Xiaomi, a technology company, founded in 2010, has grown rapidly in the technology market. According to the data from IDC for worldwide top 5 smartphone company unit market share by the third quarter of 2020, Xiaomi surpassed Apple to occupy the third market share in the world. Xiaomi's unique marketing strategy is one of the key factors of its accomplishments. However, it also suffered from poor communication strategies in terms of building a brand image that is recognized as a low-end brand. According to Ansary and Hashim, Brand image is how consumers view the brand and the association within the minds of targeted customers [3]. Therefore, it is vital for a brand like Xiaomi to improve its brand image by ameliorating its brand communication strategies. One of the most influential strategies Xiaomi applied is to continuously convey the idea that Xiaomi is a highly cost-effective brand, which provides products at the most affordable price. For the last ten years, Xiaomi has put a great amount of effort into creating highly cost-effective products. This, although helped to boost the sales of Xiaomi, it left the impression of a low-end brand, which led to the low brand image of Xiaomi. Moreover, it has caused a certain number of issues for Xiaomi, for example, the low-end brand image has been stopping Xiaomi from moving upwards into the high-end market for the past three years, which are not optimistic for Xiaomi considering the situation that the high-end market of smartphones is gradually saturating [4].

Gupta and Dhillon analyzed the business model of Xiaomi. Both in terms of sales channels and marketing models, Xiaomi has adopted a different approach from the traditional sales channels and marketing models. These innovative business models have helped Xiaomi 
to achieve success in the technology market and gradually expand its international market. In terms of profitability, capital, and technology, Xiaomi still has some problems to solve. Moreover, Xiaomi does not have the same brand appeal as Apple and Samsung and is unable to generate buzz [5]. Wang and Li studied Xiaomi's marketing strategies on social media. Xiaomi's marketing strategies, such as hunger marketing, concept marketing, event marketing, and Mi Fan culture, have all used social media to contribute well to brand sales and brand reputation. The researchers also raised the problems of Xiaomi, such as brand meaning and lack of quality, but they still praised the unique social marketing approach of Xiaomi. This marketing strategy has helped Xiaomi to create many sales miracles and gradually develop its unique marketing approach in the Internet era [6]. Xiaomi has also gained a foothold in the Indian smartphone market and Tabassum and Ahmed stated the current state of the Indian cell phone market, Xiaomi's business model, marketing mix, and innovation strategy to analyze Xiaomi's SWOT. However, due to various external factors such as the saturation of the Indian cell phone market, Xiaomi still needs to continuously innovate its strategy [7]. Xiaomi's fan culture has also been analyzed in depth. This is one of Xiaomi's most important marketing strategies, which is to cultivate a fan culture and actively listen to fans' opinions [8]. Xiaomi uses powerful social media to meet fans' expectations and demands to develop a fan-centric marketing strategy and business model [9].
Marketing, apart from promoting products and services, means promoting the brand itself and the customer's perception of the products and services [10]. Therefore, brand communication is an indispensable part of marketing strategy and an essential way to shape and communicate a brand. We found that there is a scarcity of summarizing and analyzing the relationship between Xiaomi's brand image and problems of Xiaomi's brand communication strategies. As a result, an analysis of Xiaomi's different strategies of brand communication needs to be done to identify its current problems and how these problems have affected Xiaomi's brand image in the public's mind.

\section{METHODOLOGY}

To investigate the drawbacks of Xiaomi's brand communication strategies, this research subdivided strategies of brand communication into five different parts, including public communication, interpersonal communication, social media celebrity communication, direct communication, and advertising communication. Each one of them focuses on different areas, and they jointly have a profound influence on building and shaping the brand image. The research applied here focuses on comparing the possible outcome reflected upon consumers' perspective about the five aspects of communication strategies of Xiaomi to inspect the relatively weak part in Xiaomi's brand communication strategy. Additionally, the different strategies are delivered to participants with five different statements for each brand.

Table 1 Questionnaire Structure

\begin{tabular}{|c|c|}
\hline $\begin{array}{c}\text { 1. Public Communication Strategy } \\
(\mathrm{Q} 1, \mathrm{Q} 6, \mathrm{Q} 11, \mathrm{Q} 16, \mathrm{Q} 21)\end{array}$ & $\begin{array}{c}\text { Brand understands its target audience and communicates effectively to } \\
\text { reach it. }\end{array}$ \\
\hline $\begin{array}{c}\text { 2. Interpersonal Communication } \\
\text { Strategy } \\
\text { (Q2, Q7, Q12, Q17, Q22) }\end{array}$ & $\begin{array}{c}\text { At an individual level, Brand interacts with its clients to solve any arising } \\
\text { issues (Such as having a prompt customer care). }\end{array}$ \\
\hline $\begin{array}{c}\text { 3. Direct Communication Strategy } \\
\text { (Q3, Q8, Q13, Q18, Q23) }\end{array}$ & $\begin{array}{c}\text { It is more likely that at some point in your life, a representative from Brand } \\
\text { communicated to you directly via social media, email, or a phone call. }\end{array}$ \\
$\begin{array}{c}\text { Social Media } \quad \text { Celebrity } \\
\text { Communication Strategy } \\
\text { (Q4, Q9, Q14, Q19, Q24) }\end{array}$ & $\begin{array}{c}\text { In the past 5 years, you have more likely seen an A-list celebrity featured in } \\
\text { one of Brand's social media campaigns. }\end{array}$ \\
\hline
\end{tabular}




\begin{tabular}{|l|l|}
\hline $\begin{array}{c}\text { 5. Advertising Communication } \\
\text { Strategy }\end{array}$ & $\begin{array}{c}\text { Brand's marketing campaigns are simple and full of positive user } \\
\text { experience. }\end{array}$ \\
(Q5, Q10, Q15, Q20, Q25)
\end{tabular}

By comparing the mean of different aspects of communication strategy's scores and the one with the lowest scores may be the aspects that have been affecting Xiaomi's brand communication strategy and further influence its brand image. Likewise, to further add credibility to results, researchers also gathered the same data of other four smartphone brands who are strong competitors of Xiaomi in the Chinese market, including Apple, Huawei, Vivo, Oppo [11]. The results are compared and analyzed both horizontally and vertically. The present study used a variation of Agariya et al. 's procedure, which collected data using questionnaires and examined the reliability of collected Statistics by calculating the Cronbach's alpha of different sections of the questionnaire [12]. The questionnaires are released on www.wjx.cn, which is a questionnaire platform. This study focused on systematic sampling to choose members of the population who had some background knowledge regarding the five brands. The demographics for this study included people who were at least 20 years old, and not older than 60 years. Most of the population were the working class because they could afford to buy products from these companies. To avoid bias errors, the study systematically used online surveys on people from different parts of the country, including 1038 participants from eight major provinces of China. Furthermore, the previously mentioned study by Agariya also indicates the effectiveness of this method based on their study of the effects of packaging design on brand communication. In their study, the data collected included consumers rating different packages as presented by the 5-point Likert scales, which later gave way to the areas that needed improvement as deduced from the results of the survey (Barua, 2013) [13].

Data were compared in two dimensions, which includes vertical and horizontal measurement. Data collected from consumers ' perceptions were compared horizontally with Xiaomi' s other four groups of data while data of other competitors were compared vertically with that of Xiaomi. After analyzing the questionnaire data and coming up with Xiaomi's lowest scoring brand communication strategy, the researcher collected opinions from six loyal Xiaomi fans through focus group in depth to come up with the possible causes behind the lowest communication strategy. As such, the researchers were able to identify the drawback of Xiaomi's brand communication strategies, and thus investigate the reasons behind the drawbacks and provide possible directions for the brand to improve upon and may contribute to modifying the brand's image.

\section{RESULTS}

The Cronbach Alpha is used to measure the reliability of the questionnaire. When the Cronbach Alpha is greater than 0.7 , it passes the reliability test. The statistical software SPSS 24.0 was used to test the reliability of the questionnaire data, and the results are shown in Table 2 below: the overall Cronbach Alpha coefficient of the questionnaire is 0.823 , and the Cronbach Alpha coefficient of each sub-dimension is above 0.9 , which indicates that the questionnaire of this study has a high internal consistency and passes the reliability test.

Table 2 Reliability Statistics

\begin{tabular}{|c|c|c|}
\hline & Cronbach's Alpha & N of Items \\
\hline Dimension 1 & 0.947 & $1-5$ \\
\hline Dimension 2 & 0.947 & $6-10$ \\
\hline Dimension 3 & 0.944 & $11-15$ \\
\hline Dimension 4 & 0.950 & $16-20$ \\
\hline Dimension 5 & 0.939 & $21-25$ \\
\hline Whole & 0.823 & 25 \\
\hline
\end{tabular}

The same statistical software SPSS 24.0 was used to perform the relevant statistical analysis. Before doing the factor analysis, KMO measurement and Bartlett's test were first performed on the questionnaire data to determine whether the data were suitable for factor analysis. The results of the analysis are shown in Table 3 , $\mathrm{KMO}=0.909$, and the sig $<0.001$ corresponding to Bartlett's test passed the significance test, and the data were suitable for factor analysis.

According to the principle of eigenvalues greater than or equal to 1 , and also combined with the scree plot (Figure 1) to determine the top five common factors to be extracted from the questionnaire of this study, Table 4 shows that the cumulative variance explained by the top five common factors is $82.177 \%$, that is, the top five common factors contain $82.177 \%$ of the information of the original 25 questions, which is a good explanation strength.

Table 3 Total Variance Explained

\begin{tabular}{|l|l|l|l|}
\hline Compone & Initial Eigenvalues & Extraction Sums of Squared & Rotation Sums of Squared \\
\hline
\end{tabular}




\begin{tabular}{|c|c|c|c|c|c|c|c|c|c|}
\hline \multirow{2}{*}{$\mathrm{nt}$} & \multicolumn{4}{|c|}{} & \multicolumn{4}{c|}{ Loadings } & \multicolumn{3}{c|}{ Loadings } \\
\cline { 2 - 11 } & Total & $\begin{array}{c}\% \text { of } \\
\text { Variance }\end{array}$ & Cumulative \% & Total & $\begin{array}{c}\% \text { of } \\
\text { Variance }\end{array}$ & $\begin{array}{c}\text { Cumulative } \\
\%\end{array}$ & Total & $\begin{array}{c}\% \text { of } \\
\text { Variance }\end{array}$ & Cumulative \% \\
\hline 1 & 4.779 & 19.117 & 19.117 & 4.779 & 19.117 & 19.117 & 4.164 & 16.658 & 16.658 \\
\hline 2 & 4.172 & 16.687 & 35.804 & 4.172 & 16.687 & 35.804 & 4.136 & 16.542 & 33.2 \\
\hline 3 & 4.08 & 16.319 & 52.123 & 4.08 & 16.319 & 52.123 & 4.126 & 16.505 & 49.705 \\
\hline 4 & 3.93 & 15.72 & 67.842 & 3.93 & 15.72 & 67.842 & 4.094 & 16.375 & 66.08 \\
\hline 5 & 3.584 & 14.335 & 82.177 & 3.584 & 14.335 & 82.177 & 4.024 & 16.097 & 82.177 \\
\hline
\end{tabular}

This result shows that the eigenvalues of the first five factors are greater than 1. Starting from the sixth factor, the scree plot tends to be smooth, so it is reasonable to extract the first five common factors.

Table 4 shows the rotated factor loadings matrix. The results of the analysis show that Q16-Q20 have high loadings on common factor 1 , and these five questions are mainly used to investigate celebrity communication strategies; Q6-Q10 have high loadings on common factor 2 , and these five questions are mainly used to investigate interpersonal communication strategies: Q1-Q5 have high loadings on common factor 3 , and these five questions are mainly used to investigate public communication strategies; Q11-Q15 have high loadings on common factor 4 , and these five questions are mainly used to investigate direct communication strategies; Q21-25 have high loadings on common factor 5. These five questions are mainly used to investigate direct communication strategies.

In summary, the questionnaire of this study has high reliability and validity and can be used for subsequent analysis.

Table 4 Rotated Factor Loadings Matrix

\begin{tabular}{|c|c|c|c|c|c|}
\hline & \multicolumn{5}{|c|}{ Component } \\
\hline & 1 & 2 & 3 & 4 & 5 \\
\hline Q1 & & & 0.906 & & \\
\hline Q2 & & & 0.911 & & \\
\hline Q3 & & & 0.911 & & \\
\hline Q4 & & & 0.902 & & \\
\hline Q5 & & & 0.907 & & \\
\hline Q6 & & 0.909 & & & \\
\hline Q7 & & 0.908 & & & \\
\hline Q8 & & 0.902 & & & \\
\hline Q9 & & 0.907 & & & \\
\hline Q10 & & 0.913 & & & \\
\hline Q11 & & & & 0.904 & \\
\hline
\end{tabular}




\begin{tabular}{|c|c|c|c|c|}
\hline Q12 & & & 0.906 & \\
\hline Q13 & & & 0.905 & \\
\hline Q14 & & & 0.904 & \\
\hline Q15 & & & 0.898 & \\
\hline Q16 & 0.912 & & & \\
\hline Q17 & 0.916 & & & \\
\hline Q18 & 0.904 & & & \\
\hline Q19 & 0.912 & & & \\
\hline Q20 & 0.913 & & & \\
\hline Q21 & & & & 0.872 \\
\hline Q22 & & & & 0.908 \\
\hline Q23 & & & & 0.885 \\
\hline Q24 & & & & 0.908 \\
\hline Q25 & & & & 0.907 \\
\hline \multicolumn{5}{|c|}{ Extraction Method: Principal Component Analysis. } \\
\hline \multicolumn{5}{|c|}{ Rotation Method: Varimax with Kaiser Normalization. } \\
\hline
\end{tabular}

Table 5 Quantitative Results

\begin{tabular}{|l|l|l|l|}
\hline & & Average Score & Number of Responders \\
\hline Apple & Q1 & 3.84 & 1038 \\
\hline & Q2 & 3.81 & 1038 \\
\hline & Q3 & 3.57 & 1038 \\
\hline & Q4 & 3.8 & 1038 \\
\hline Huawei & Q5 & 3.84 & 1038 \\
\hline & Q6 & 3.65 & 1038 \\
\hline
\end{tabular}




\begin{tabular}{|c|c|c|c|}
\hline & Q8 & 3.51 & 1038 \\
\hline & Q9 & 3.63 & 1038 \\
\hline & Q10 & 3.64 & 1038 \\
\hline \multirow[t]{5}{*}{ Oppo } & Q11 & 2.89 & 1038 \\
\hline & Q12 & 2.91 & 1038 \\
\hline & Q13 & 2.89 & 1038 \\
\hline & Q14 & 2.91 & 1038 \\
\hline & Q15 & 2.93 & 1038 \\
\hline \multirow[t]{5}{*}{ Vivo } & Q16 & 2.98 & 1038 \\
\hline & Q17 & 2.97 & 1038 \\
\hline & Q18 & 3 & 1038 \\
\hline & Q19 & 3.01 & 1038 \\
\hline & Q20 & 2.98 & 1038 \\
\hline \multirow[t]{5}{*}{ Xiaomi } & Q21 & 2.35 & 1038 \\
\hline & Q22 & 3.13 & 1038 \\
\hline & Q23 & 3.89 & 1038 \\
\hline & Q24 & 3.14 & 1038 \\
\hline & Q25 & 3.13 & 1038 \\
\hline
\end{tabular}

The quantitative results are as shown in Table 5 below. The data was collected from 1038 participants nationwide with the help of www.wjx.cn in China.

Among the five strategies of Xiaomi, the public communication strategy has the lowest scores of 2.35, which is 1.54 points away from Xiaomi's highestscoring strategy: direct communication strategy (3.89).

In addition, Xiaomi also scored the lowest among the five brands in comparison to the other four brands' public communication strategies, which is 1.49 points away from the highest public communication strategy score among these five brands: Apple (3.84).

\section{DISCUSSION}

After above analysis, it seems that Xiaomi has failed in the area of public communication, which is not an expected result for a brand with more than 200 million active users in its own consumer community: $\mathrm{Mi}$ Community [14]. In other words, Xiaomi has developed a clear understanding of its targeted audience. Moreover, Xiaomi is obligated to respond to consumers' reported issues and maintain an active atmosphere around the community. Besides that, Xiaomi has defined its relationship with consumers as interdependent friendship. From all the information above, it may conclude that Xiaomi has a significant amount of experience communicating with its consumers. However, the survey results of consumers' perspectives indicate the opposite outcome. The online questionnaire 
survey consists of 1038 participants who have experience using at least two brands among the five brands: Xiaomi, Apple, Huawei, Vivo, OPPO. The result suggests that Xiaomi ranked the lowest among the five brands with an average of 2.35 out of all samples. The discussion result of the focus group suggests that the possible one of the reasons behind this outcome may be related to Xiaomi's pricing strategy, which allows Xiaomi to focus on the low-end-market of China, and that is similar to the customer positioning of Pinduoduo: an e-commerce platform similar to Taobao but aims at the low-end market of China and its main advantage is its low pricing strategy. Besides the population of first and new first-tier cities of China, there is still more than 1.2 billion population, which consists of the majority of China's consumption power [15]. Xiaomi took advantage of the low-end market and attracted millions of consumers in the past ten years. However, in November 2020, one of Xiaomi's executives: Mei Wang, claimed during a public speech that whoever wins the support of "Diaosi" wins the market, and such statement went viral on social media and raised heated discussion among consumers [16]. "Diaosi" is a Chinese noun that describes someone who achieves nothing in their life and earning only the amount of salary that can barely provide for themselves, in other words, Diaosi means loser in English [17]. Such a statement was calling Xiaomi's customers losers. Xiaomi then declared an announcement to apologize about the event within the first 24 hours. However, the side effects remain strong. The topic raised over 160 million views on Weibo, a Chinese famous social media platform [18]. Under this topic, a voting post was released to the public with a topic of "Whether consumers will continue to use Xiaomi's products or not". With over 23,900 participants, over 11,800 participants state that they will no longer use the products of Xiaomi. [19]. From the above information, it may conclude that such a statement had not only severely damaged Xiaomi's reputation but also consumers' loyalty to Xiaomi. Diaosi Event had not only severely damaged Xiaomi's reputation but also consumers' loyalty to Xiaomi.

The other reason showed by the focus group discussion result is that Xiaomi applies many tactics of exaggerated publicity. For example, MIUI 12 is the latest user interface system of Xiaomi's mobile phone, which contains a great number of cutting-edge technology features such as a 100-megapixel camera, which can produce photographs with a significant number of details [20]. At the launch event, Xiaomi promised that MIUI 12 will service consumers as a smooth, advanced, and brand-new user interface system and provide consumers with an extraordinary user experience. However, after several major system updates, Xiaomi still failed to keep its promise made at the product conference. Due to the difficulty of summarizing keywords that can represent negative comments. Therefore, the researcher's manual selected 1,000 comments from the discussion section of MIUI 12.5, and 768 of them are negative ones criticizing the system [21]. The keywords researchers applied included but were not restricted to statements such as overheated battery issue, system breakdown, and freeze. A launch event is a way to communicate directly with the public and spread information [22]. It directly establishes the initial impression of a new product in the minds of consumers. Xiaomi's approach gives consumers the feeling that they are being deceived when they find out that the product does not function as advertised, which is something that no amount of good after-sales service can compensate for. To sum up, there are two particular reasons for Xiaomi's failure in public communication. One is a statement that is damaging Xiaomi's brand image the other is exaggerated advertising content and they are both essential for building brand's image and by improving on areas that are related to these two topics, Xiaomi may be able to find a way to improve its brand image and eventually expand its market share of the high-end market of smartphone.

\section{CONCLUSION}

Brand communication plays a crucial role in shaping the brand image, and the problem Xiaomi faces today is that it urgently needs to improve its brand image. In the research on Xiaomi, most of the current studies have analyzed the strengths and weaknesses of Xiaomi's marketing strategies. The study of Xiaomi's brand communication is a gap in the current research field on Xiaomi. This paper focuses on the brand communication strategy of Xiaomi's marketing strategy to identify the problems that are currently preventing Xiaomi from enhancing its brand image. The scores of Xiaomi and its competitors' brand communication strategies were collected through a questionnaire based on the Likert scale in different regions of China. Although the level of knowledge participants possess about the five brands are uneven but considering the popularity and fame of the five brands majority of consumers have the basic and necessary knowledge to complete the questionnaire, which outweighs the shortcoming mentioned above.

The researcher compared the scores of Xiaomi's own communication strategies vertically and the scores of each communication strategy under different brands horizontally to find the strategy with the lowest score: public communication strategy.

The empirical results reveal that Xiaomi's public communication strategies not only scores the lowest than its rest communication strategies but also ranked 
the lowest among its competitors. The researchers made a focus group which consisted with Xiaomi's loyal customers to come up with the main reasons for Xiaomi's low scores in this strategy: exaggerated promotional method and consumer-insulting statement. This failed strategy has affected Xiaomi's brand image to a certain extent. There is a limitation to improve the brand communication and marketing strategy of Xiaomi by only addressing the issues that Xiaomi is facing today to improve its brand image. Improving brand image requires a company to manage and improve various aspects such as technology, brand culture, etc. However, this study is useful for the brand communication aspect of Xiaomi. In the highly competitive cell phone market, this study provides a detailed analysis of brand communication to help Xiaomi realize the issues that are currently hindering brand image enhancement. Moreover, this study could provide research directions for other researchers. A study of a brand's communication can be very beneficial to the brand image of the brand.

\section{REFERENCES}

[1] Zehir, Cemal., et al. "The Effects of Brand Communication and Service Quality in Building Brand Loyalty through Brand Trust; the Empirical Research on Global Brands." Procedia - Social and Behavioral Sciences 24.1 (2011): 1218-31.

[2] Xu, Fangqi. "A Smartphone Challenger's Competitive Strategy: The Case of Xiaomi." 3 (2015): 90-99.

[3] Ansary, Amin., and Nik Mohd Hazrul Nik, Hashim. "Brand Image and Equity: The Mediating Role of Brand Equity Drivers and Moderating Effects of Product Type and Word of Mouth." Review of Managerial Science 12 (2017): 969-1002.

[4] Guo, Yingqiu., and Jincheng, Ni. "A 6ps-Based Analysis of Htc Company's Marketing Strategies in Mainland China." Chinese Business Review 20.3 (2021): 100-05.

[5] Gupta, Sonam., and Ishneet, Dhillon. "Can Xiaomi Shake the Global Smartphone Industry with an Innovative 'Services-Based Business Model'?" Journal of Management \& Research 8.3 (2014): 114.

[6] Wang, Xiaobin., and Yaofei, Li. "Marketing Strategy Analysis of Xiaomi Phone Based on Social Media." International Conference on Mechatronics, Electronic, Industrial and Control Engineering (MEIC 2014). Atlantis Press, 2014.

[7] Tabassum, Rahela., and Shehbaz, Ahmed. "Xiaomi Invades the Smartphone Market in India." Decision:
Official Journal of the Indian Institute of Management Calcutta 47.2 (2020): 215-28.

[8] Li, Mmingwei., et al. "Fans as a Source of Extended Innovation Capabilities: A Case Study of Xiaomi Technology." International Journal of Information Management 44 (2019): 204-08.

[9] Shih, Chao-Ching., et al. "Fan-centric social media: The Xiaomi phenomenon in China." Business Horizons 57.3 (2014): 349-358.

[10] Bernoff, Josh., and Charlene, Li. "Harnessing the Power of the Oh-So-Social Web." IEEE Engineering Management Review 38.3 (2010): 815 .

[11] Information from Vendor's market share of smartphone shipments in China from 1st quarter 2014 to 4th quarter 2020: https://www.statista.com/statistics/430749/chinasmartphone-shipments-vendor-market-share/

[12] Agariya, Arun, K., et al. "The Role of Packaging in Brand Communication." International Journal of Scientific \& Engineering Research 3.2 (2012): 1-13.

[13] Barua, Ankur. "Methods for Decision-Making in Survey Questionnaires Based on Likert Scale." Journal of Asian Scientific Research 3.1 (2013): 35-38.

[14] Information from Mi Fan Meetups: https://c.mi.com/aboutus/index

[15] Information from Estimated population of first and new first tier cities in China in 2020, by city: https://www.statista.com/statistics/992683/chinapopulation-in-first-and-second-tier-cities-by-city/

[16] Information from Executives said "whoever wins the support of Diaosi wins the market", Xiaomi responded:

https://baijiahao.baidu.com/s?id=16843483606609 $73163 \&$ wfr $=$ spider $\&$ for $=p c$

[17] Yang, Peidong., et al. "Diaosi as Infra-politics: Scatological Tropes, Identity-Making and Cultural Intimacy on China's Internet." Media, Culture \& Society 37.2 (2015): 197-214.

[18] Information from Wang Mei from Xiaomi said that whoever wins the support of Diaosi wins the market in the future: http://s.weibo.com/weibo?q=\%23\%E5\%B0\%8F\% $\mathrm{E} 7 \% \mathrm{~B} 1 \% \mathrm{~B} 3 \% \mathrm{E} 7 \% 8 \mathrm{E} \% 8 \mathrm{~B} \% \mathrm{E} 5 \% \mathrm{~B} 5 \% 8 \mathrm{~B} \% \mathrm{E} 7 \% \mathrm{~A}$ 7\%B0\%Е6\%9C\%AA\%Е6\%9D\%A5\%Е5\%ВE\%97 $\% \mathrm{E} \% \mathrm{~B} 1 \% 8 \mathrm{C} \% \mathrm{E} 4 \% \mathrm{~B} 8 \% 9 \mathrm{D} \% \mathrm{E} 8 \% 80 \% 85 \% \mathrm{E} 5 \%$ BE\%97\%Е5\%A4\%A9\%Е4\%B8\%8B\%23

[19] Information from Wang Mei apologized for her comments and resigned. Will you continue to buy 
Xiaomi's product after hearing Wang Mei's comments:

https://m.weibo.cn/2517830513/457486992645708 3

[20] Information from Xiaomi MIUI 12 global update bug tracker: Issues reported \& fixed so far: https://piunikaweb.com/2021/05/22/miui-12global-update-bug-tracker/

[21] Information from MIUI System: https://www.xiaomi.cn/board/558495

[22] Information from MIUI 12 Global Launch Event Recap:

https://www.youtube.com/watch?v=aO7QSFQcfv8 